\title{
TEACHER AS A FACILITATOR OR A TEACHER: EMPOWERING LEARNING STRATEGIES IN GEOMETRY COURSE
}

\author{
Wanda Nugroho Yanuarto \\ Mathematics Education Program, The University of Muhammadiyah Purwokerto \\ wandanugroho86@gmail.com
}

\begin{abstract}
Teaching is the well known word for teachers. Teachers know the meaning of this word and know how to perform teaching. Sometimes they do not know the difference between teaching and facilitating in learning and it make a distance between the students and teachers. The purpose of this study are how learning geometry in mathematics education, Teacher Training and Education Faculty at the University of Muhammadiyah Purwokerto, Indonesia modify the class in geometry course interactively and can be easily understood by students. So, the researchers made the strategies in geometry course that is associated with the games. Games are one of strategy in class which is support for the student to understand the geometry with easily and make the class interactively.
\end{abstract}

Keywords: Teacher, learning strategies, and geometry course

\section{INTRODUCTION}

Mathematics is a subject that every student has to study at one time or another. Some love it but if being honest, most people hate studying math (Sheeffield, 1995; McFarlane, 2002). Based on Groff (2010) the importance of math for students has never been more prominent and Haylock (1984) said that most university courses include some level of math while almost every profession uses math in some form on a daily basis. The problem many students have is that they don't know how to study math to get good results (Fleith, 2000; Tall, 1977).

Ross (2000) said that how to Learn Math is a free self-paced class for learners of all levels of mathematics. It combines really important information on the brain and learning with new evidence on the best strategies to approach and learn math effectively. Ironically that many students have had negative experiences with math, and end up disliking math or failing (Hennessdy, 1997; Hashimoto, 1997). This geometry class will give learners of math the information they need to become powerful math learners, and it will teach them about their own potential to succeed and the strategies needed to approach math effectively. (Gardner, 1991; Linda, 2003; Paulsen, 1999) if students have had past negative experiences with math this will help change your relationship to one that is positive and powerful.

Not all students like math, but a good math teacher has the power to change that. A good math teachers can help students who have traditionally struggled with arithmetic begin to build confidence in their skills. For students who are usually bored with numbers, a good math teacher can breathe new life into the subject. A good math teacher makes her class a place where students want to be.

Sloan (1996) said that many textbooks and students will say that math teachers should have an extensive knowledge and love of math. This is very helpful, but if math is not the sole reason that get up each morning, don't worry. A healthy command of mathematics literacy is just fine. Correctly with Tayman (1996) that good primary math teacher, in particular, seem to possess an endless amount of patience, because there are many different ways that students actually learn math. And they learn at many different speeds. Math teacher are not frustrated by do-over. Or complete start over. 
Understanding Piaget's theory on how youngsters create logic and number concepts is time well spent for math teacher. It underscores the necessity of knowing their students, so teacher can serve them well.

Teachers who facilitate personal growth in students are unique, extraordinary, worthy of the dedication. It requires a self assurance, a willingness to share self, to care, to begin a journey, then launch the student on a personal quest which may not be shared; to send the student beyond the teacher, perhaps with the student never realizing or appreciating what was given (Stenberg, 1995; Ken, 2004). It is that unqualified and indefinable difference between training and education, bossing and leading, telling and teaching. Six characteristics which identify teachers who are high facilitators of personal growth: 1) effective listening; 2) genuineness; 3) understanding; 4) respect; 5) intelligence; and 6) skill in interpersonal communication (Ken, 2004).

Active learning strategies provide very smart teaching learning opportunities to teachers Forsyth, 1991). If teacher is able to create an active learning environment in his class, he has to help the students in learning in various ways. Active learning methodologies are able to make teaching very smart and easy. Teachers may use collaborative learning and try to do an exciting experiment in his class. (de Sonza, 1998; Dolan, 2012 ) said that nn modern learning environment, we see that "learning" is a more popular word than "teaching". Teachers have to understand the modern trends in teaching learning process. Teachers have to make learning more interesting and interactive, so that students may learn better.

Many math courses suffer from the following issues: (Bobango, 1993)

- The teachers don't know why they are teaching particular math topics, and they often don't know what else the students are learning in other subjects.

- As a result, the students don't know why they learn those math topics, either. The common question, "Why do we have to learn this?", is a reasonable one. Do you have a good answer, beyond "It's in the exam" or worse, "Because it's good for you"?

The role of teacher is changing in smart and active learning methodologies. (Egenfeldt, 2007) told that now teacher is as a facilitator in learning. Teaching and learning are being modified due to innovations in education. In this article we are discussing about teacher's role in changing learning environment. In many teaching class situations, the role of the teacher is that of facilitator of learning: leading discussions, asking open-ended questions, guiding process and task, and enabling active participation of learners and engagement with ideas. However, small groups function and behave in various ways and have different purposes. Teachers therefore need to be able to adopt a range of roles and skills to suit specific situations, often during the same teaching session.

This issue focuses on helping the teacher to move away from the deliverer of knowledge in a passive environment, to one where all students are actively engaged in the construction of their knowledge in geometry class.

\section{RESEARCH DESIGN AND METHODE}

This research is a qualitative descriptive study based learning stages of lesson study. The study was conducted in the first semester of the academic year of 2014/2015 at the University of Muhammadiyah Purwokerto (UMP). The subjects of this study is the first semester students of class A UMP Mathematics Education that cover in Geometry Course of odd semester academic year of $2014 / 2015$.

a. Plan

The research was conducted by four cycles with each cycle stages are follow:

The purpose of this stage is to design learning that provides solutions to the problems and event arise ever conducted by teacher models. At this stage, the teacher and the observers do plan what will do for next meeting. Implementation of this phase is a teacher provides learning tools to observer then performed an evaluation of the plan. Learning tools consists of a unit of learning teacher event, seating charts, and lesson observation sheet. Lessons are conducted in a studentcentered learning with the aim of encourage the students creativity.

b. Do 
The aim of this stage is to carry out the accordance with the planning of learning that has been produced on plan stage. At this phase, the teacher teaching practice with the agreement on the plan stage. The teacher and students activities are based on the lesson plan which has been agreed. Observer must record students activities that require attention and development of creativity. The observers guide based on observation is student seating, lesson plan, and observation sheets. This observer guide is in accordance with the agreement that has been formed at the stage of the plan.

c. See

The purpose of this stage is to perform reflection and evaluation of the implementation of learning on Do stage. Implementation of this phase begins with the presentation of a model for the implementation of instructional faculty that has been done. Teacher model provides self-reflection on what is perceived and what happens during the activity of learning take place. The teacher can also reveal the difficulties experienced during the implementation of learning. Activities in this phase continued with the presentation by the teacher observer on finding obtained during the implementation Do stage. The findings that can be either positive or negative on the implementation of learning. The next activity at this stage is feedback from the observer which consists of many problems that they got. The result of this stage can be good discussion on the next cycle.

The collecting data from this study are:

\section{a. Observation}

The observations made during the learning process that is on the Do stage. Implementation of the observations made by the observers. The observation sheets consist of questions about implementation of learning, encouraging the creativity and many problems that found by the observer during the learning process

b. Questionnaire

The questionnaire was given to the students in order determine the learning process and encouraging creativity of students after the learning process in class. The questionnaire were used in the form of statements enclosed to describe the creativity and learning process in students.

c. Documentation

The documentations used in form of video recording, photos and files of students from each implementation of plan, do, and see.

The data that have been obtained and analyzed qualitatively. Those data was found by data reduction, data presentation, and conclusion. Data reduction is focused on activities related to student creativity in learning. From the results of data reduction, it will be presented in pictures or description of explanation. Next analyzed is performed conclusion by observing and combining of various data obtained.

\section{The Classroom Meetings}

In this section The authors give a short impression of how the classroom meetings went. For a written meeting-by-meeting account we refer to the extended research report (widjaja, 2002). The very first meeting suffered severely from two things. Firstly, due to a college event, the teacher had found little time to prepare the course and to acquaint himself well enough with the tools and equipment. Secondly, the course class could be made it like the figure below. 


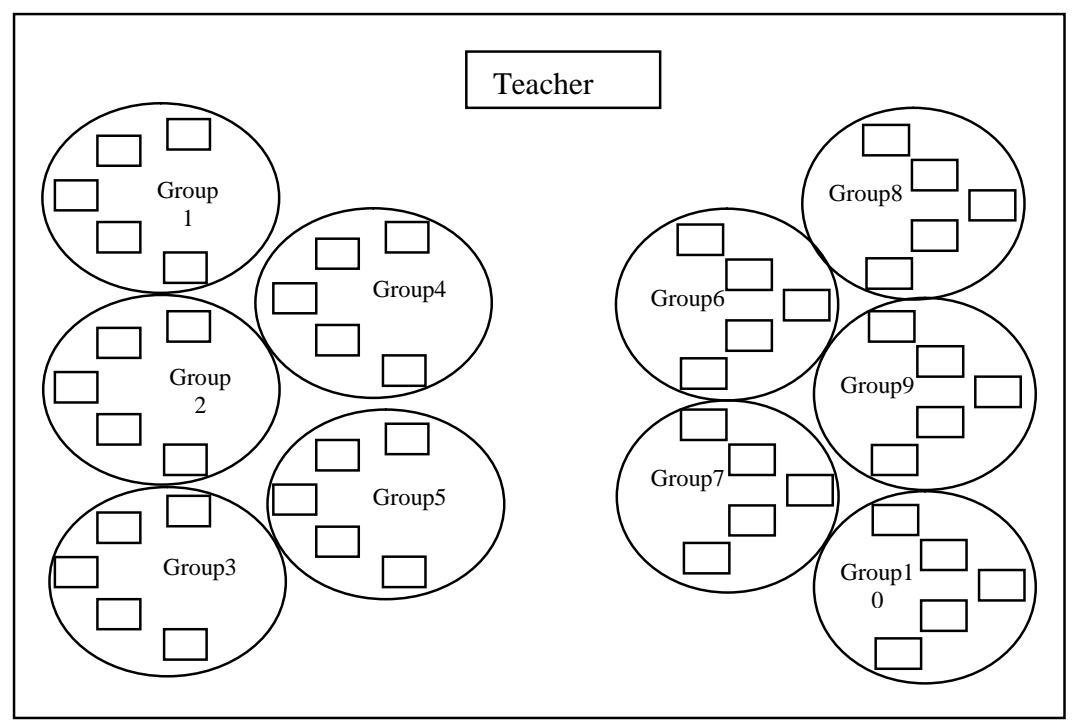

Figure 1. Set up of the classroom. The rectangles represent chairs (one circle was 5 chairs)

The class was only 100 minutes, which was really too short for meeting. Although the students evinced as well as in the upcoming gaming works. Learning in class begins with the division of the group by the teacher to the students. One group consisted of 5 students, this means that there are 10 groups. The number of students in the lecture Geometry are 46 students in the group there are 5 students and 4 students. Learning is done very regularly. Students were divided into groups on the basis of their intelligence level so that the group can consist of students whose level of intelligence evenly. Prior to the implementation of the games are done, students are asked to look for ongoing learning concept. This process is carried out to find out the creativity of students in learning and collaboration with members of the group. Occasional teacher around to find out if the discussion process can run smoothly. After the discussion looking concepts being studied. Teacher gives a brief description of related concepts that sought students to have a common vision and concept. Once students know and understand the concept, teacher gave a briefing on the rules of the games.

\section{DISCUSSION}

To optimize the learning outcomes, the learning process should use a whole-brain approach. According to Balka (1974), when humans communicate with words, the brain at the same time have to find, sort, formulate, tidy up, organize, connect, and make a mixture of ideas with words that already have that meaning can be understood. At the same time, these words strung together with a picture, symbol, image (impression), sounds, and feelings. A set of words that no sequential mixed in the brain, came out one after another, connected by logic, and generate meaning can be understood.

Playing is a common phenomenon that occurs in all the human. Playing is a flurry of selfselected without no element of coercion. It fits perfectly with the spirit of imaginative students. So if nurtured properly, it can support encouraging creativity of students learning. In addition, an important means game to socialize the student become a member of a community so that they get to know and appreciate other community members, but unfortunately many parents consider the case that the game is not important, so they often ignore. Of course, if this is allowed that could threaten the encourage students learning creativity.

Nowadays the need for the development of the education system in Indonesia is increasing from year to year. Was once considered the most effective conventional systems and has been applied in the teaching and learning activities, but this learning system is no longer able to keep up with the times. Based on that later emerged a new learning method that is expected to increase students's interest in learning.

According to Colburn (2000) geometry occupies a special position in the secondary mathematics curriculum, because of the many concepts contained therein. From the psychological point of view, the geometry of an abstract representation of the visual and spatial experience, eg field, 
pattern, measurement and mapping. Meanwhile, from the standpoint of mathematics, geometry provides approaches to solving problems, such as images, diagrams, coordinate system, vectors, and transformation. Geometry is also an environment to study the mathematical structure.

Usiskin argued that:

- The geometry is a branch of mathematics that studies the visual patterns,

- The geometry is a branch of mathematics that connect mathematics with the physical world or the real world,

- The geometry is a way of presenting a phenomenon that does not look or not physical, and

- The geometry is a mathematical system example

The purpose of learning geometry is that the students gain confidence about her math skills, be a good problem solver, able to communicate mathematically, and to reason mathematically. Beside that learning geometry is developing the ability to think logically, develop spatial intuition, imparting knowledge to support other materials, and can read and interpret mathematical arguments. Basically geometry has a greater opportunity to understand the students compared with other branches of mathematics. This is because the ideas of geometry already known by students since before they enter school, for example, line, plane and space. However, the evidence on the ground shows that the geometry of learning outcomes is low and needs to be improved. In fact, among the various branches of mathematics, geometry occupies the position of most concern.

There is a significant difference between the learning strategy using games and without game. The learning strategy using the game can increase creativity, imagination, and innovation in students. So with interactive educational games, learning can be done effectively and efficiently. Teaching and learning process will run fun and not boring. By contrast, the learning strategy without using the game. The ability of creativity, imagination, and innovative in students is not so well developed as a method of learning that only focus on theoretical basis alone. So that this kind of learning methods by some students felt quite boring and that is the one reason why students become lazy in learning.

Games in geometry course has many advantages. In addition students are not bored in the study, the subject matter becomes younger transmitted from teacher to student. In addition, interactive educational are also able to condense the time required to complete a competency because with this game the students more quickly capture the lessons that can save time to educate them. In this study, strategies who teacher can do in geometry class is game. The games that can implemented in class such as:1) guess and check game; 2) mystery box; and 3) secret inside balloon.

\section{G uess and $C$ heck $\mathrm{G}$ ame's Process}

Determine what students are trying to find. The learning begins with the division of the group. Each group consisted of 5 students. Each group will be taught how they look for the most appropriate alternative answers of some of the issues presented in the paper. But before they look for alternative answers, first they must find the concept of the material being studied today by discussed with a group of their friends. This process is very intensive because the thinking of students with their friends in group will improve their ability to think critically. The results is getting their search results with friends. Therefore lecture needs to be intensively give a help for students because the students have been looking for a concept that they should do and her friends. After they did the research for the concept they get the goal, the goal is the same perception of the concept that what has been produced has a shared the knowledge. 


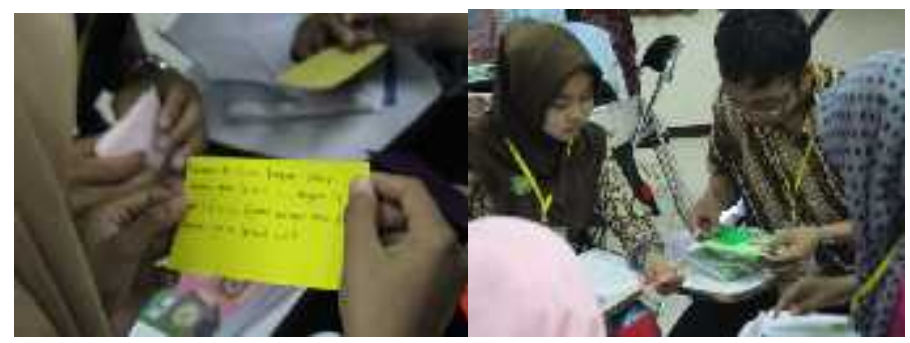

Figure 2. student determined what they try to find

Determine what number students are comparing to. The results of what they get together group of their friends then compared with the results conducted by other groups, whether of the discussion draft is done and the results of the search of alternative answer to the problem is provided. This process needs to be done so that what they do does have a truth value or not

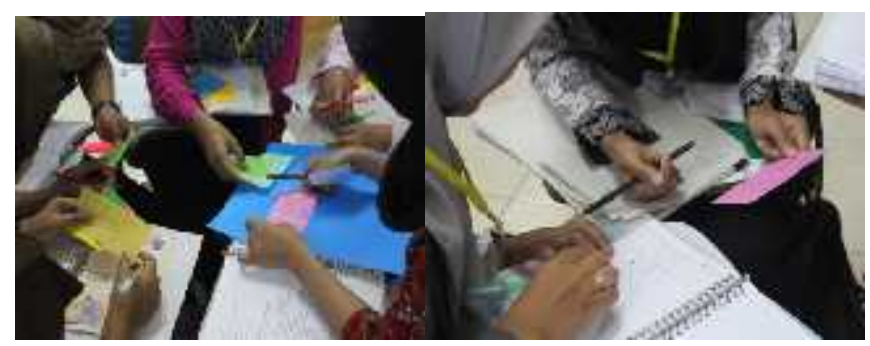

Figure 3. student determined what they are comparing to

Try out a number. The searching of alternative answer to the problem presented teachers need to be analyzed by using the method and specific answer. This search process requires trial and error. The results obtained have the right to perform a lengthy process, which is then corrected by the first trial group of their friends and then analyzed again to the results obtained have the truth.

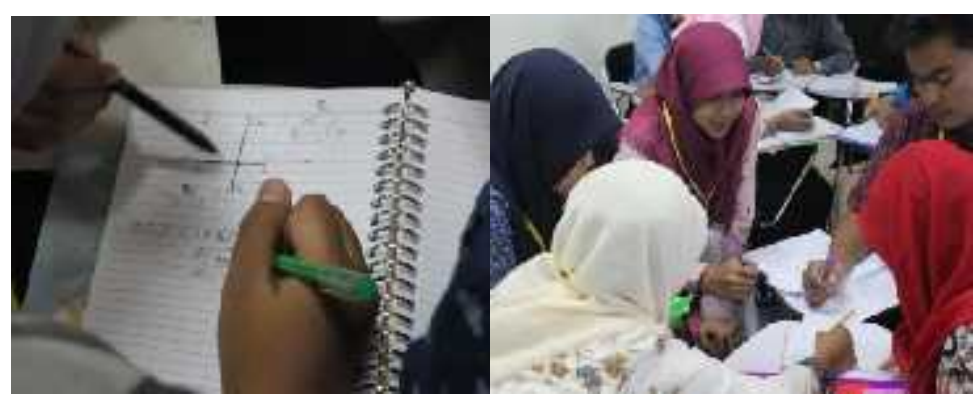

Figure 4. student try out a number

If students are close to their number but not quite there yet, determine what should be done. The process of finding alternative answers needed timeless, if its given time has run out while the student has not completed the given problem teacher, then students need to correct myself whether management has owned the right time or not. So not only have good cognitive abilities but time management and division of tasks between the groups also need to be considered by each group of student learning. 


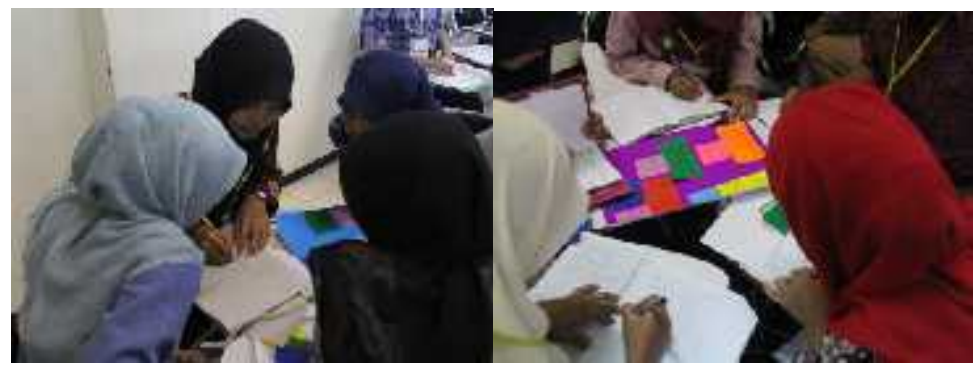

Figure 5. student determined what should be done if it is not quite finish yet

Once students are done, check to make sure the numbers really work by plugging them back into the original conditions. The alternative answers that have been obtained by each group has a different way of reference and different for each group. So when it has a difference by each group of teachers need to consider whether the means used was appropriate or not. Restore step by step do need to figure out which one has the most appropriate alternative answers.

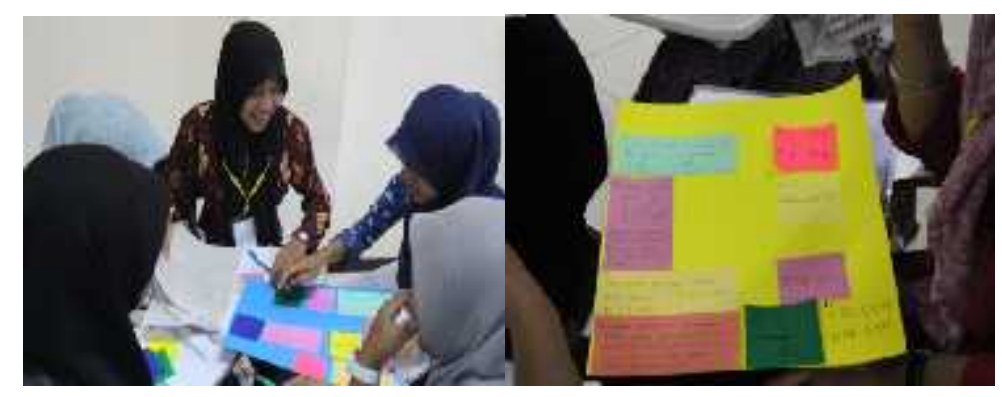

Figure 6. Student check their final answer

\section{Mystery Box}

The interest in game based learning has accelerated considerably in recent years. Developers and researchers are working in every area of game based learning, including games that are goal oriented, social game environments, non digital games that are easy to construct and play. (Ross, 2000; Tayman, 1996) Games developed experessly for education and commercial games that lend themselves to refining team and group skills. More complex approaches like role playing, collaborative problem solving, and other forms of simulated experiences have broad applicability across a wide range of disciplines, and are beginning to be explored in more classrooms. Using gaming as a vehicle for learning is a very powerful idea and one that is under utilized. There are so many ways teacher can do with games in their classroom, such as:

- Team Building Games: Some of most common games used in education are games intended to build relationships between two people or between teams. In a classroom setting, where team games may lack in the teaching of information they make up for by teaching communication and cooperation skills.

- Board and Card Games: boar games, card games and other individual activities are good motivational tools in education. These games teach students to learn from their mistakes and accomplish goals while simultaneously having fun. While supportive of games as a supplement to education, contends that the best way for a student to learn something is by someone teaching it directly to them.

- Electronic Games: video games and computer games are becoming more accepted in the school environment because most student have an element of expertise in electronic gaming, their capacity to learn in that real will be higher than in a typical classroom setting. 
- Edutainment: as technology advances and students are exposed to video games, television and the internet at younger ages, educators are increasingly interested in "edutainment"", or combination of education with entertainment. Using technology in a learning environment is especially helpful when students are learning complex topics because it develops "higher order thinking skills:.

- Drawbacks to Edutainment: although most teachers agree that there are benefits to fusing electronic gaming with education, many teachers haven't received adequate training as games to feel comfortable using an electronic game in their curriculum. The benefit of a game can only extend so far without the support of a knowledgeable teacher. Because students need a teacher to link the game to specific lesson, it is essential for teacher to understand games before applying them to the classroom.

Many various ways that can do by the teachers to make classroom learning process more interesting for students, so the authors make a strategy in its class by Mystery Box Games. It is created by team building combines board games and card games. Mystery Box can be done by groups with each group was given the responsibility to carry out the game together. Form of the games is using the box which there is a score inside. The score can be achieved by the group that can solve the problem, otherwise if it can not resolve the problem, then the group will get a penalty in the form of a reduction in the existing score in the box. Each group is obliged to make a problem and solve it. Then the problem written on paper and put in a box that has been provided. Box is then to another group to finish. Each member of the group assigned to analyze and explore the completion of the existing problems. This game process can be performed to assess creativity, responsibility, and student active in class.

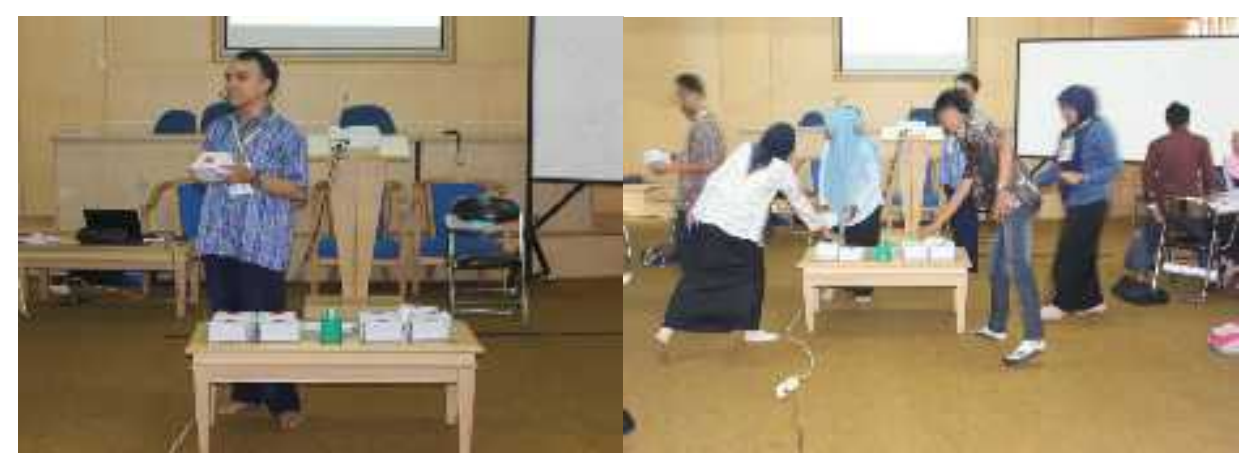

Figure 7. Teacher provides guidance to students about mystery box

\section{Students activities in Secret Inside Balloon Game}

a. Make one problem which related by material on learning today and made on the paper.

Learning begins with the process of finding a concept that is based on group discussions. Each group must find a concept that is being studied. Once the concept is found by each group learning, teachers provide direction to integrate perception and concept created by students. Once the concept is embedded, then created a problem that is based on the concept that the issue was made in a piece of paper that has been provided by the teacher. This step is the first step in secret inside balloon game. 

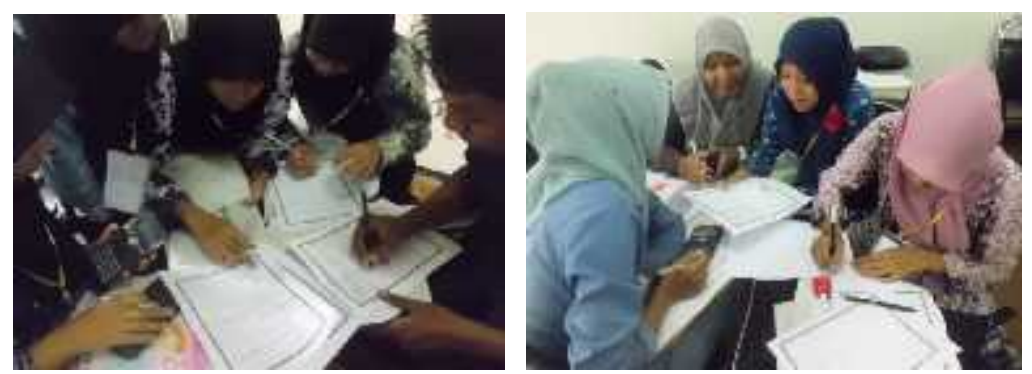

Figure 8. Students discuss with their group about creating one problem and an answer key for it

b. Make the key answer of the question on a separate sheet of paper about

Problems that have been made by each group, and then made the key answers to these problems. Problems are created and then put into the balloon, blow up it and given to another group to be resolved. The process of solving problems that exist are given a time limit of 10 minutes.

c. Each balloon is available with a different value with the auction system

In the balloon are already available value that could be obtained if the group can solve the problems that exist in the balloon. If the group can not solve existing problems or settlement is done wrong then the value will be reduced in accordance with what is in the balloon.
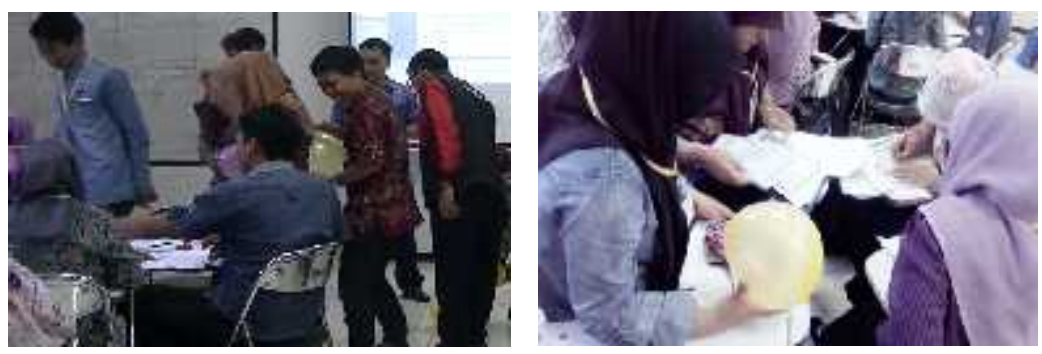

Figure 9. Students blow up the balloon which is take the problem inside previously

d. Then the balloon is opened and do on the problems that exist in it. If the matter is done right, then the value which obtained in accordance with the existing value in each balloon.

In every balloon there is a problem to be solved by each group learning. The problem is the concept of learning is done that day. So after children seek material concept of geometry, they are trying to create problems and solve them. The value obtained from any content on these problems, if any participant wrong or could not solve existing problems, then they will be reduced in value based on the value they get from the contents of the balloon.

e. Conversely, if the matter can not be done obtained or done incorrectly, then the group will be reduced in accordance with the value of the value in the balloon.

The problems should be solved obtained with bounded time, Each group should have a performance, strategy, and how to resolve the problem well and quickly. When they do not have a good strategy, then they will be difficult to solve existing problems, because the problem is timeless. The groups that resolve problems that exist in the balloon properly, then the value obtained will be in accordance with the value stated in the balloon, on the contrary, if they fail and wrong doing, then the value will be reduced in accordance with the value they get inside the balloon.

\section{CONCLUSION}

Learning geometry requires a variety of ways to do. The problem is how a teachers could make them self as a facilitator or simply transfer a concept only. Therefore, it is necessary to an understanding and knowledge of how to teach geometry not only to improve their skills on the 
geometry but how to make a teacher becomes a facilitator and increase their ability to improve the active students in the classroom.

A variety of games that have been described above may be able to increase the understanding and knowledge of the reader will be learning geometry fun as well as make professional teachers not only include science concepts in the classroom, but how to conceptualize be interactive and professional in class. Finally, I hope this research will stimulate others to continue the research, verify, modify, or apply it.

\section{Acknowledgement}

The authors would like to thank to Ahmad as The Dean of Teacher and Training Faculty in University of Muhammadiyah Purwokerto for his critical comments and encouragement during the research project. And last but not least, the authors would like to thank to my lovely wife Aulia Nisa Khusnia and my baby Adam for giving me spirit, support, and love.

\section{Note}

The author conducted this research study as his final project in Lesson Study in Mathematics Education, University of Muhammadiyah Purwokerto, Central Java, Indonesia.

\section{REFERENCES}

Bobango, T. (1993). Geometry and Analytic Calculus. New York : Routledge

Baker, Scott and Gersten, Russell. (1998). Teal World Use of Scientific Concepts: Integrating Situated Cognition with Explicit Instruction. California: Exceptional Students Press

Balka,C. (1974). Affective Dimensions of Learning. South California: Thomson Wadsworth

Colburn, Alan. (2000). An Inquiry Geometry. Toronto: Science Scope

Davis, R. (1969). Students's Ideas in Science. United Kingdom: Open Press.

De Sonza, F.D. (1998). Development of Mathematical Communicaton in Problem Solving Groups by Language Minority Students. New York: Mc. Graw hill companies

Dolan, R.P., Goodman, J., \& Strain-Seymour, E. (2012). Evaluation of a Game-Based Performance Task for Measuring Collaborative Problem Solving Skills. Paper presented at the annual meeting of the American Educational Research Association, Vancouver, BC, Canada

Egenfeldt-Nielsen, S. (2007). Third Generation Educational Use of Computer Games, Journal of Educational Multimedia and Hypermedia, 16(3), 263-281

Embretson, S.E. (1987). Improving the Measurement of Spatial Aptitude by Dynamic Testing. Intelligence 11(4), 333-358

Evan,G. I. (1964). A summary of a Study of Schooling: Some Finding and Hypotheses. Toronto: Phi Delta Kappan

Fleith, Denise de Sonza. (2000). Lecturer and Student Perceptions of Creativity in the Classroom Environment. New Jersey: Lawrence Erlbaum Associates, Publishers

Forsyth, D.R. \& McMillan, J.H. (1991). What Teories of Motivation Say about Why Learners Learn. New Directions for Teaching and Learning. 45: 39-51

Gardner, H. (1991). Abschied vom IQ-Die Rahmentheorie der Vielfache Intelligenzen. Stuttgart, (Orig.: Frames of mind)

Getzels,G.,\& Jackson,F.S. (1962). Teaching Science with Toys and Gaming. California: College Teaching Summer Press

Groff, J., Howells, C., \& Cranmer, S. (2010). The Impact of Console Games in the Classroom: Evidence from schools in Scotland. UK: Futurelab

Hashimoto. (1997). Opening Assessment to Our Students Social Education. Alabama: The University of Alabama Press.

Haylock. (1984). Science Education. New York: Learning Express

Hays, R.T. (2005). The Effectiveness of Instructional Games: A Literature Review and Discussion. Orlando, FL: naval Air Warfare Center Training Division. Retrieved from http://www.dtic.mil/cgi-bin/GetRDoc?AD=ADA441935

Hennessdy, Beth A. (1997). Teaching for Creative Development: A Social-Psychological Approach. Needman Heights, MA: Allyn \& Bacon. 
Jensen,I. (1973). Character Countism. Washington: National Academy Press

Karen Zill is the former Manager of Educational Outreach at WETA, Washington, D.C. She is currently an independent consultant who writes educational materials, develops outreach campaigns, and conducts media literacy classes and workshops.

Ken Bain, What the Best College Teachers Do, Harvard University Press, 2004, pages 32-42.

Kiili, K. (2005). Educational Game Design: Experiental Gaming Model Revisited. Research Report 4. Tampere University of Technology. Retrieved from http://amc.pori.tut.fi/publications/EducationalGameDesign.pdf

Kohler, L. (1997). How to make hands-on science work for you. New York: Eric Clearinghouse on Information and Technology

Linda Nilson, Teaching At Its Best: A Research-Based Resource for College Instructors, $2^{\text {nd }}$ edition, Anker Publishing, 2003, pages 41-44.

Malone, T.W. (1981). Toward a Theory of Instrinsically Motivating Instruction. Cognitive Science, 5(4), 333-369

Matt DeLong and Dale Winter, Learning to Teaching and Teaching to Learn Mathematics: Resources for Professional Development, Mathematical Association of America, 2002, pages 159-168.

McFarlane, A., Sparrowhawk, A., \& Heald, Y. (2002). Report on the Educational use of Games: An Exploration by TEEM of the Contribution which Games Can Make to the Education Process. Cambridgeshire, UK

Paulsen, M.B., \& Feldman, K.A. (1999). Student Motivation and Epistemological Beliefs. New Directions for Teaching and Learning. 78: 17-25

Ross, Michael Elsohn. (2000). Science Their Way. Young Students, pp 63.

Singh,Y.E. (1988). School Science in Gaming. London and New York: The Penguin Group

Sloan, Megan. (1996). I love Geometry. California: College Express Group

Sheeffield,et.al. (1995). First- and Second-Grade Students Communication in Mathematics. Teaching Students Mathematics. Toronto: Thomson Wadsworth

Stenberg \& Lubart, (1995). Using Think Time and Wait Time Skillfully in the Classroom. Texas: ERIC Digest

Tall, D.O. (1977). Conflicts and Catastrophes in the Learning of Mathematics, Mathematical Education for teaching, 24, $2-18$

Tayman, Juliann M. and Thompson, Kathleen Lewis. (1996). Taking the Chaos out of Cooperative Learning: the 3 most Important Components. New Jersey: The Clearing House Company in Press

Thurstone, L.L. (1950). Some Primary Abilities in Visual Thinking. Psychometric Laboratory Research report no. 59, Chicago: University of Chicago Press

Widjaja, Y.B. (2002). How Realistic Approach and Gaming Based Lesson Work in Indonesian Secondary School Classroom [On-line]. Unpublished master's thesis, University of Amsterdam, the
http://www.science.uva.nl/research/math/examen/2002/widjaja.pdf

Available: 